\title{
Modeling and Analysis of Internal-Tide Generation and Beamlike Onshore Propagation in the Vicinity of Shelfbreak Canyons
}

\author{
Weifeng G. Zhang, Timothy F. Duda, And Ilya A. Udovydchenkov \\ Applied Ocean Physics and Engineering Department, Woods Hole Oceanographic Institution, Woods Hole, Massachusetts
}

(Manuscript received 13 August 2013, in final form 10 October 2013)

\begin{abstract}
A hydrostatic numerical model with alongshore-uniform barotropic $\mathrm{M}_{2}$ tidal boundary forcing and idealized shelfbreak canyon bathymetries is used to study internal-tide generation and onshore propagation. A control simulation with Mid-Atlantic Bight representative bathymetry is supported by other simulations that serve to identify specific processes. The canyons and adjacent slopes are transcritical in steepness with respect to $\mathrm{M}_{2}$ internal wave characteristics. Although the various canyons are symmetrical in structure, barotropicto-baroclinic energy conversion rates $C_{v}$ are typically asymmetrical within them. The resulting onshorepropagating internal waves are the strongest along beams in the horizontal plane, with the stronger beam in the control simulation lying on the side with higher $C_{v}$. Analysis of the simulation results suggests that the cross-canyon asymmetrical $C_{v}$ distributions are caused by multiple-scattering effects on one canyon side slope, because the phase variation in the spatially distributed internal-tide sources, governed by variations in the orientation of the bathymetry gradient vector, allows resonant internal-tide generation. A less complex, semianalytical, modal internal wave propagation model with sources placed along the critical-slope locus (where the $\mathrm{M}_{2}$ internal wave characteristic is tangent to the seabed) and variable source phasing is used to diagnose the physics of the horizontal beams of onshore internal wave radiation. Model analysis explains how the cross-canyon phase and amplitude variations in the locally generated internal tides affect parameters of the internal-tide beams. Under the assumption that strong internal tides on continental shelves evolve to include nonlinear wave trains, the asymmetrical internal-tide generation and beam radiation effects may lead to nonlinear internal waves and enhanced mixing occurring preferentially on one side of shelfbreak canyons, in the absence of other influencing factors.
\end{abstract}

\section{Introduction}

Shelfbreak canyons can be characterized by complex three-dimensional flows. Winds, shelf waves, and ambient shelf currents can drive subinertial flows, enhancing the exchange of shelf and open-ocean waters (Allen and Durrieu de Madron 2009). Steep topography of canyons can trap remotely generated internal waves (IWs) (Chiou et al. 2011; Hotchkiss and Wunsch 1982; Jachec et al. 2006; Kunze et al. 2002), cause resonant amplification of tidal flow (Swart et al. 2011), and foster local generation of internal tides (Gregg et al. 2011; Hotchkiss and Wunsch 1982), offering a few explanations for observed mixing enhancement in shelfbreak

Corresponding author address: Weifeng G. Zhang, Applied Ocean Physics and Engineering Department, Woods Hole Oceanographic Institution, 266 Woods Hole Road, MS\#12, Woods Hole, MA 02543.

E-mail: wzhang@whoi.edu canyons (Gregg et al. 2011; Lee et al. 2009; Shroyer 2012). IWs can also radiate onshore from shelfbreak canyons and, if enhanced relative to noncanyon areas, may increase mixing.

As a continuation of our prior work on IW generation at a shelfbreak (Zhang and Duda 2013), this study focuses on asymmetrical internal-tide generation in idealized symmetrical shelfbreak canyons and the beam patterns of shoreward depth-integrated baroclinic energy fluxes on the shelf. Asymmetrical IW generation in a canyon, a major topic here, has already been observed in a numerical model (Petruncio et al. 2002). Specifically, modeled internal-tide energy is stronger within the upstream side of the canyon, in the sense of coastaltrapped wave propagation, even when the canyon bathymetry and offshore barotropic tidal forcing are symmetrical with respect to the canyon axis. Petruncio et al. (2002) attributed the asymmetrical pattern to Earth's rotation with no explanation provided. Additionally, synthetic aperture radar images of the Hudson Canyon 
region [e.g., Fig. 6 in the New York Bight section of Jackson (2004)] and the North Mien-Hua Canyon [e.g., Fig. 2 in Duda et al. (2013)] show IWs on the upstream side propagating away from the canyons, with upstream and onshore direction components. Also, beam patterns of depth-integrated baroclinic energy fluxes away from IW source regions in the deep ocean have been observed in numerical models (Carter 2010; Rainville et al. 2010), with formation attributed to constructive interferences of IWs generated at different source regions.

This work aims to unveil the dynamics of asymmetrical internal-tide generation in shelfbreak canyons, and the resultant onshore beam radiation, using numerical simulations and semianalytical analyses. The numerical simulations with idealized canyon bathymetry quantify the asymmetrical patterns under nearly complete dynamics (section 2), and the semianalytical analyses provide a qualitative explanation of the beam radiation pattern based on the physics of extended wave sources (section 3). The cross-canyon asymmetrical internal-tide generation pattern is then discussed in section 4 with the help of numerical sensitivity experiments. The findings are summarized in section 5 .

\section{Numerical modeling}

\section{a. Configuration of the numerical model}

The Regional Ocean Modeling System (ROMS; Shchepetkin and McWilliams 2005) is used for the simulations. The hydrostatic pressure approximation is used, which is justifiable because long-wavelength internal tides, the primary interest of this study, have small vertical acceleration. The model is set up in Cartesian coordinates with the positive $x$ direction pointing offshore, positive $y$ along-shelf, and positive $z$ pointing upward. A rectangular domain is used with edge lengths of $L_{x}=1933 \mathrm{~km}$ and $L_{y}=134.8 \mathrm{~km}$. The bathymetry of the primary "control" simulation (Fig. 1a) is given by

$$
\left\{\begin{array}{l}
H=\max \left[0, h_{w}\left(\frac{x}{x_{i}-x_{c}}+1\right)\right]+h_{0} \tanh \left(\frac{x_{c}-x}{L_{s}}\right)-h_{1} \\
x_{c}=x_{1}-L_{c} \exp \left[-\frac{\left(y-L_{y} / 2\right)^{2}}{2 W_{c}^{2}}\right]
\end{array} .\right.
$$

Here, $x_{i}=41 \mathrm{~km}, x_{1}=104.5 \mathrm{~km}$, the cross-shelf scale of the slope $L_{s}=16.5 \mathrm{~km}$, the depth scale of the shelf $h_{w}=$ $65 \mathrm{~m}$, the vertical scale of the slope $h_{0}=465 \mathrm{~m}$, and $h_{1}=$ $540 \mathrm{~m}$, and, in the control simulation (Table 1), the length and width scales of the canyon are $L_{c}=L_{c 0}=$ $10 \mathrm{~km}$ and $W_{c}=W_{c 0}=5 \mathrm{~km}$, respectively. The control run parameter values are chosen to represent topography of the Mid-Atlantic Bight (MAB) continental shelf, shelf edge, and canyons. Note that the steepest bathymetric slopes offshore of the shelfbreak both within and outside of the canyon are supercritical to $\mathrm{M}_{2}$ IWs. Here, critical means the seabed slope $\alpha(z)$ is equal to the square root of $\left(\omega_{\mathrm{M}_{2}}^{2}-f^{2}\right) /\left[N\left(z_{b}\right)-\omega_{\mathrm{M}_{2}}^{2}\right]$, the slope of $\mathrm{M}_{2}$ frequency internal wave characteristics at the seabed, where $\omega_{\mathrm{M}_{2}}$ is the $\mathrm{M}_{2}$ frequency, $f$ is the inertial frequency, and $N\left(z_{b}\right)$ is the buoyancy frequency at the seabed. Also note that higher values for the length parameter $L_{c}$ produce steeper slopes within the canyon. The 100-m isobath is $75 \mathrm{~km}$ offshore, and the maximum depth is restricted to $1000 \mathrm{~m}$ to maintain model vertical resolution in the deep sea. The resolution is $300 \mathrm{~m}$ in the along-shelf direction; resolution in the cross-shelf direction is $242 \mathrm{~m}$ within $175 \mathrm{~km}$ of the coast (the study area) and increases gradually to $12 \mathrm{~km}$ toward the offshore boundary. There are 100 stretched vertical layers with enhanced resolution near the surface and bottom (about $0.2 \mathrm{~m}$ at the shelf break). The Coriolis parameter $f$ is a constant corresponding to $39^{\circ} \mathrm{N}$.

Along-shelf uniform tidal elevation of $\mathrm{M}_{2}$ frequency is prescribed on the deep-sea (eastern) boundary, where Chapman (1985)-, Flather (1976)-, and Orlanski (1976)type radiation conditions are used for sea level elevation, barotropic momentum, and all baroclinic variables, respectively. A $600-\mathrm{km}$-wide sponge layer is included next to the offshore boundary (outside of the study domain) to prevent reflection of the IWs. Across the domain, the coastal boundary is a solid wall of 10-m height. Periodic boundary conditions are used in the along-shelf direction. The model uses generic length scale $k-k l$-type vertical mixing parameterization (Warner et al. 2005) with no explicit horizontal viscosity or diffusivity. Quadratic bottom drag is used with a drag coefficient $C_{d}=0.003$. The model has no heat, salt, or momentum exchange with the atmosphere.

The tidal elevation at the offshore boundary is tuned to generate shelfbreak (100-m isobath) barotropic tidal currents with amplitudes $U_{0}=0.1 \mathrm{~m} \mathrm{~s}^{-1}$ and $V_{0}=0.07 \mathrm{~m} \mathrm{~s}^{-1}$ 

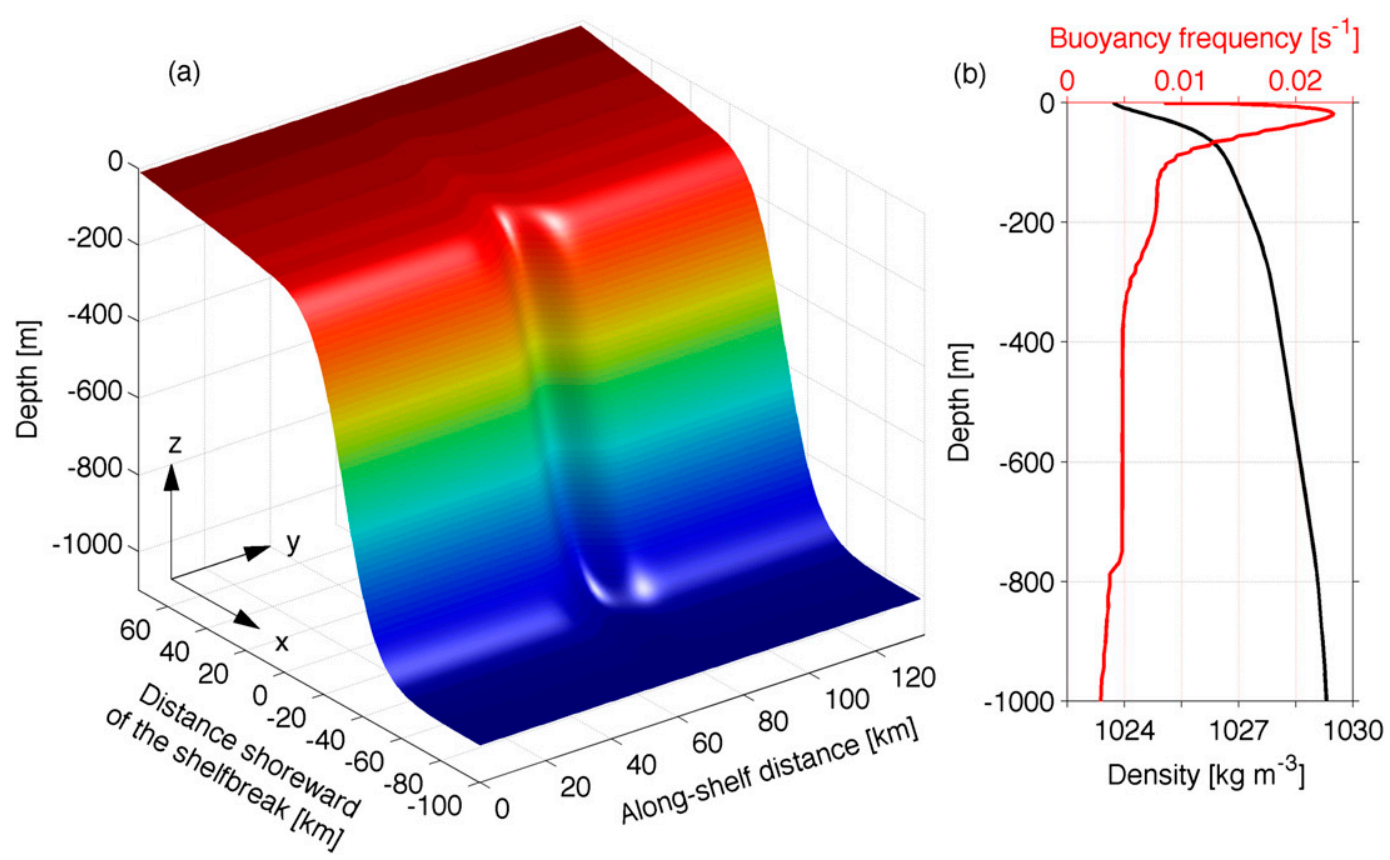

FIG. 1. For the control simulation (Table 1) (a) bathymetry and (b) initial stratification are shown.

in the cross- and along-shelf directions (Fig. 2a), respectively, similar to those observed at MAB shelfbreak. The resulting barotropic tidal rotation is clockwise everywhere and phases are almost uniform in the alongshelf direction, largely consistent with the $\mathrm{M}_{2}$ tide at MAB shelfbreak [see Fig. 1 in Zhang and Duda (2013)]. Except for the slope criticality parameter, the boundary forcing determines the baroclinic tidal generation parameter regime. The tidal excursion parameter, the ratio of the tidal excursion length $(\sim 1.5 \mathrm{~km})$ to the characteristic horizontal length scale $\left(L_{s}\right)$, is much smaller than one. The Froude numbers $\left(U_{0} / c_{n}\right)$ computed using internal wave modal wave speeds $c_{n}$ are subcritical for approximately the first six modes.
To examine the influence of various factors, a total of 13 numerical simulations (including the control one) were conducted (Table 1). All model simulations start from rest with horizontally uniform density structure (Fig. 1b) from an MAB summertime climatology (Zhang et al. 2011). Because simulations show no change in the spatial pattern of internal-tide propagation on the continental shelf after 6 tidal periods, all analyses are conducted on tidal periods 7 and 8.

\section{b. Numerical results}

Consistent with the finding of Petruncio et al. (2002), the IW field within the canyon in the control simulation has an asymmetrical form (Figs. 3b,c), with higher

TABLE 1 . The list of ROMS simulations where along-shelf span is $L_{y}$, canyon width is $2 W_{c}$, and canyon length is $L_{c}$.

\begin{tabular}{|c|c|c|c|c|c|c|c|}
\hline Run & Description & $L_{y}(\mathrm{~km})$ & $2 W_{c}(\mathrm{~km})$ & $L_{c}(\mathrm{~km})$ & $\begin{array}{l}\text { Expansion distance } \\
\text { at canyon axis }(\mathrm{km})\end{array}$ & $\begin{array}{l}\text { Sense of tidal } \\
\text { rotation }\end{array}$ & Figures \\
\hline 1 & Control run & 134.8 & 10 & 10 & 0 & Clockwise & 2,3 , and 5 \\
\hline 2 & Extended along-shelf span & 215.5 & 10 & 10 & 0 & Clockwise & $4 a-d$ \\
\hline 3 & Along-shelf expanded canyon axis 1 & 215.5 & 40 & 10 & 30 & Clockwise & $4 \mathrm{e}-\mathrm{h}$ \\
\hline 4 & Along-shelf expanded canyon axis 2 & 215.5 & 70 & 10 & 60 & Clockwise & Not shown \\
\hline 5 & Opposite rotation & 134.8 & 10 & 10 & 0 & Anti-clockwise & Not shown \\
\hline 6 & Wide canyon 1 & 134.8 & 20 & 10 & 0 & Clockwise & $8 a-d$ \\
\hline 7 & Wide canyon 2 & 134.8 & 15 & 10 & 0 & Clockwise & Not Shown \\
\hline 8 & Narrow canyon 1 & 134.8 & 7.5 & 10 & 0 & Clockwise & Not Shown \\
\hline 9 & Narrow canyon 2 & 134.8 & 5 & 10 & 0 & Clockwise & $8 \mathrm{e}-\mathrm{h}$ \\
\hline 10 & Long canyon 1 & 134.8 & 10 & 20 & 0 & Clockwise & Not Shown \\
\hline 11 & Long canyon 2 & 134.8 & 10 & 15 & 0 & Clockwise & $9 a-d$ \\
\hline 12 & Short canyon 1 & 134.8 & 10 & 7.5 & 0 & Clockwise & Not Shown \\
\hline 13 & Short canyon 2 & 134.8 & 10 & 5 & 0 & Clockwise & $9 \mathrm{e}-\mathrm{h}$ \\
\hline
\end{tabular}




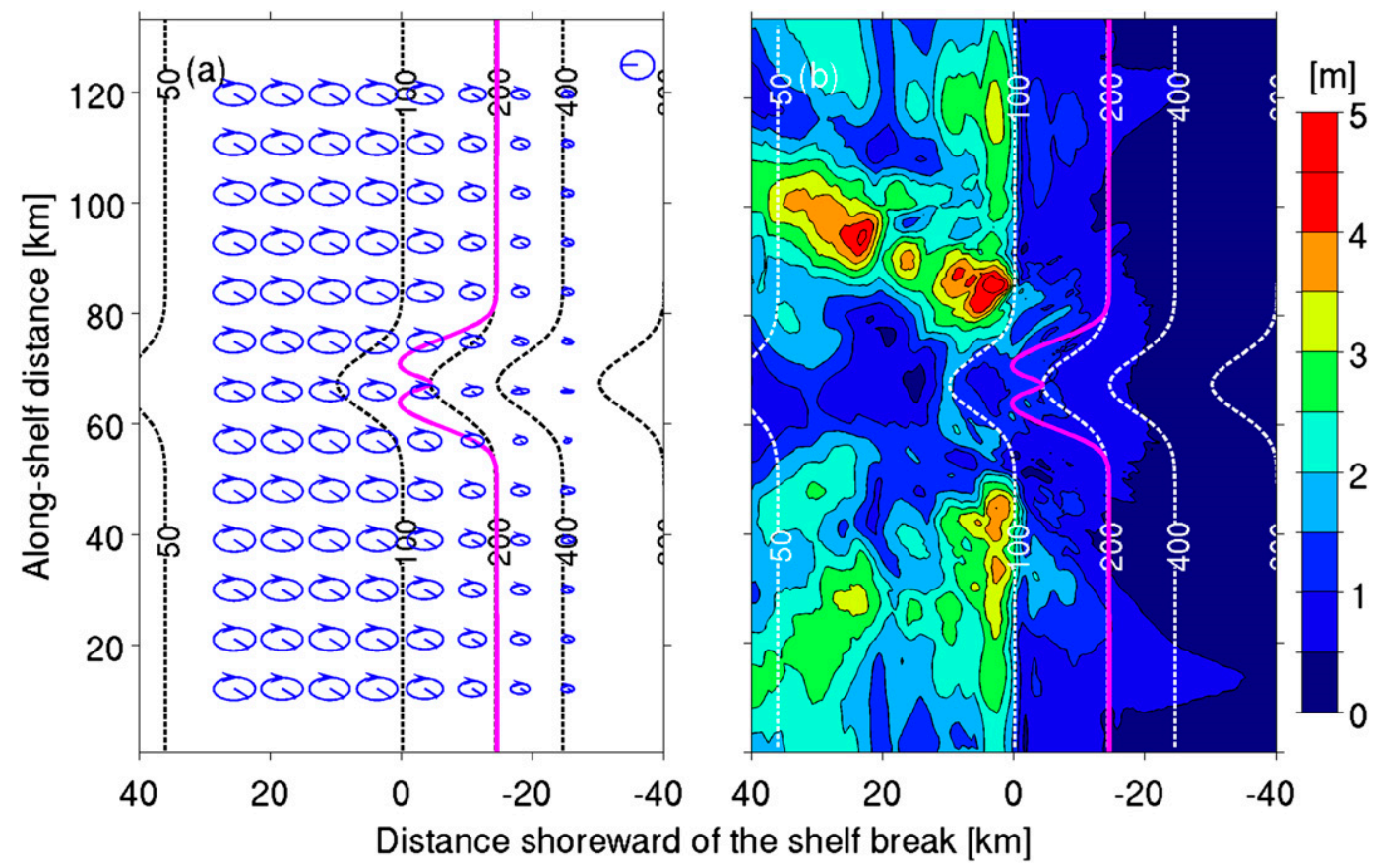

FIG. 2. (a) Ellipses and phases of the barotropic tide; (b) max displacement of the isopycnal surface for density anomaly $\sigma=25$ (mean depth $25 \mathrm{~m}$ ), each computed over tidal cycles 7 and 8 of the ROMS control simulation. The dashed lines in (a) and (b) are isobath contours ( $\mathrm{m}$ ); the ellipse at the upper-right corner of (a) is a scale for the tidal current having major and minor axes of $0.1 \mathrm{~m} \mathrm{~s}^{-1}$.

amplitudes on the upstream side (northern side in the MAB). Vertically integrated barotropic-to-baroclinic energy conversion rate $C_{v}$ reaches its peak on the northern canyon slope (between lines D and F; Fig. 3a), with $C_{v}=\int\left\langle\rho^{\prime} g W\right\rangle d z, \rho^{\prime}$ is perturbation density, $g$ is gravitational acceleration, and $W=-\nabla_{h} \cdot\left[\mathbf{U}_{h}(z+H)\right]$ is the vertical velocity of the barotropic flow. Furthermore, $\nabla_{h}=(\partial / \partial x, \partial / \partial y), \mathbf{U}_{h}$ is the horizontal barotropic velocity vector, and $\langle\cdot\rangle$ represents the time average over tidal periods 7 and 8 . The along- $y$ line segments $\mathrm{A}-\mathrm{B}, \mathrm{B}-\mathrm{C}$, et cetera, in Fig. 3d, mark sections used for the analysis of $C_{v}$ in ROMS and also mark prescribed along-shelf source variability in the simplified wave model (section 3 ). The slope-averaged $C_{v}$ is about 3 times higher between lines $\mathrm{D}$ and $\mathrm{F}$ than it is away from the canyon (between lines $\mathrm{A}$ and $\mathrm{B}$ or between lines $\mathrm{F}$ and $\mathrm{G}$ ) and 25 times higher than it is on the southern canyon slope (between lines B and D).

The model also shows an asymmetrical onshore radiation of baroclinic energy extending toward the northwest and southwest from the canyon (Figs. 3b,c). On the shelf, vertically integrated baroclinic energy flux $\mathbf{F}_{v}=$ $\int\left\langle\mathbf{u}^{\prime} p^{\prime}\right\rangle d z$ and IW kinetic energy $E_{v}=\int E_{k} d z=$ $\int\left(\rho_{0}\left\langle\mathbf{u}^{\prime} \cdot \mathbf{u}^{\prime}\right\rangle / 2\right) d z$ both reach peak values in a beam extending northwestward from the critical locations on the northern canyon flank between lines $\mathrm{E}$ and $\mathrm{F}$, while the beam south of the canyon is weaker and starts from the critical locations outside of the canyon perimeter (south of line B). Here, $\mathbf{u}^{\prime}$ and $p^{\prime}$ are baroclinic velocity and perturbation pressure, respectively, and $\rho_{0}$ is the reference density. Patterns of the energy flux offshore of the critical locations are more complex. Within the canyon, strong baroclinic energy flux pointing offshore to the southeast starts from the critical locations on the northern flank of the canyon. Note that the patterns of $\mathbf{F}_{v}$ and $E_{v}$ are not sensitive to the along-shelf coverage of the model, as indicated by Run 2 with a larger $y$ dimension (Figs. $4 \mathrm{a}-\mathrm{d}$ ).

Cross-shelf sections of $E_{k}$ (Fig. 5a) show that IW energy is concentrated in cross-shelf-oriented beams that are tangent to the ocean floor at the critical locations; that is, IWs radiate both onshore and offshore from the critical locations along the beams. The highest $E_{k}$ on the shelf is near the surface in an area $20-30 \mathrm{~km}$ north of the canyon and $10-20 \mathrm{~km}$ onshore of the shelfbreak (see S4 in Fig. 5a), corresponding to the $E$ peak in Fig. 3c. Figure 5b shows irregularity in the along-shelf distribution of $E_{k}$, in particular, the discontinuity of the cross-shelf beam above the canyon and the relatively strong $E_{k}$ at the beam depth on both flanks of the canyon (e.g., see S9 in Fig. 5b). 


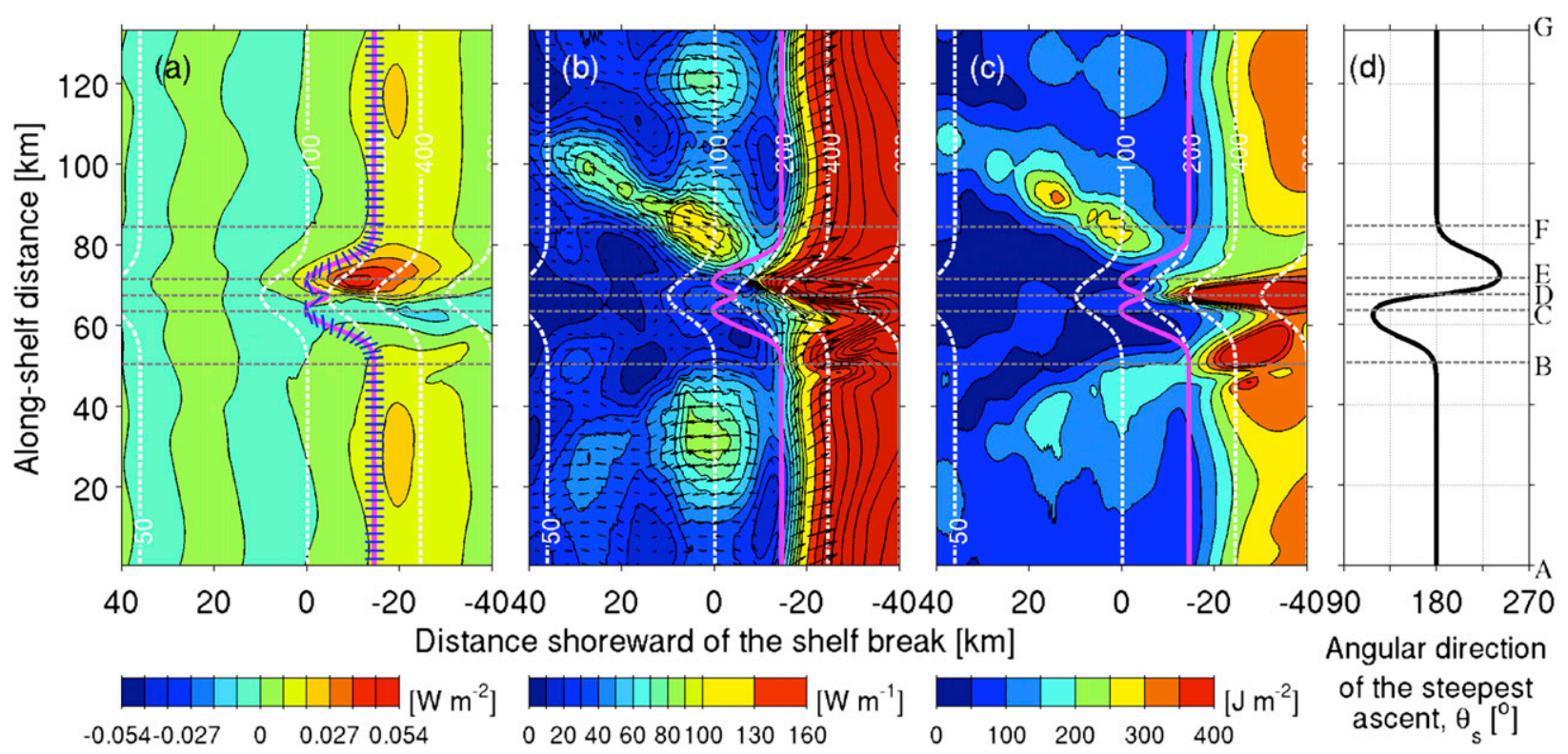

FIG. 3. Results from the ROMS control simulation are shown. Vertically integrated (a) barotropic-to-baroclinic energy conversion rate $C_{v}$, (b) baroclinic energy flux (color depicts magnitude), and (c) baroclinic (internal wave) kinetic energy density. (d) The direction of the steepest ascent along the critical-slope locus is shown, also drawn with short blue lines in (a). The locus is shown with magenta lines in (a)-(c). This direction is computed with the positive angle defined as clockwise to be consistent with the barotropic tidal rotation and is computed relative to the east. Deep-water arrows of energy flux greater than $160 \mathrm{~W} \mathrm{~m}^{-1}$ are omitted in (b) for clarity. The white dashed curves are isobath contours (m). The gray dashed lines separate the line source in the control run into segments, and the names of the lines (A-G) are given on the right of (d).

\section{Semianalytical wave propagation model}

\section{a. Model description}

To identify the mechanism responsible for the asymmetrical onshore baroclinic wave beam radiation pattern (Fig. 2), we construct a semianalytical model that captures the main IW generation and propagation effects in the vicinity of the canyon. The two-dimensional (2D) model includes unimodal $\mathrm{M}_{2}$-frequency IW sources distributed along a curved line in the horizontal plane, the line being the critical-slope locus along the seabed. The wave-source parameters are derived from the bathymetry, background stratification, and nonuniform $C_{v}$ given by the numerical simulation.

The equation governing normal modes of linear harmonic IW vertical velocity $w$ is (Apel 1987; Vlasenko et al. 2005)

$$
\frac{d^{2} w}{d z^{2}}+\frac{N^{2}(z)-\omega^{2}}{\omega^{2}-f^{2}} k^{2} w=0
$$

Here, $N$ is the buoyancy frequency, $\omega$ is the IW frequency, and $k$ is the horizontal wavenumber. With the assumptions of zero velocity at the seabed and surface, the solution for a given frequency $\omega$ in the situation of uniform depth and stratification provides the normal modes, with each mode (eigenfunction of index $n$ ) having the shape $\psi_{n}(z)$ and $k=k_{n}$. Writing $w=$ $\sum_{n} A_{n}(x, y) \psi_{n}(z) e^{-i \omega t}$, exploiting the flat seafloor assumption (eliminating mode coupling), and considering the case $\omega \ll N$, the complex amplitude $A_{n}(x, y)$ of each mode is described by the Helmholtz equation (Rainville and Pinkel 2006):

$$
\frac{\partial^{2} A_{n}}{\partial x^{2}}+\frac{\partial^{2} A_{n}}{\partial y^{2}}+k_{n}^{2}(x, y) A_{n}=0 .
$$

The neglecting of mode coupling and the flat bottom assumption are justifiable because mode-coupling coefficients, which would appear in the right-hand side of (3) if included, when computed for the ROMS model conditions (with sloping seafloor), using expressions in Griffiths and Grimshaw (2007), are allowably small on the shelf. Using the forced inhomogeneous form of (3), modal amplitude from multimode laterally distributed delta function sources can be written as an integral over the source locations (spatial subscript $s$ )

$$
w(x, y, z, t)=\iint_{s} \sum_{n} \hat{A}_{s n}\left(x_{s}, y_{s}\right) G_{n}\left(x-x_{s}, y-y_{s}\right) \psi_{n}(z) e^{-i\left[\omega t+\phi_{s n}\left(x_{s}, y_{s}\right)\right]} d x_{s} d y_{s}
$$




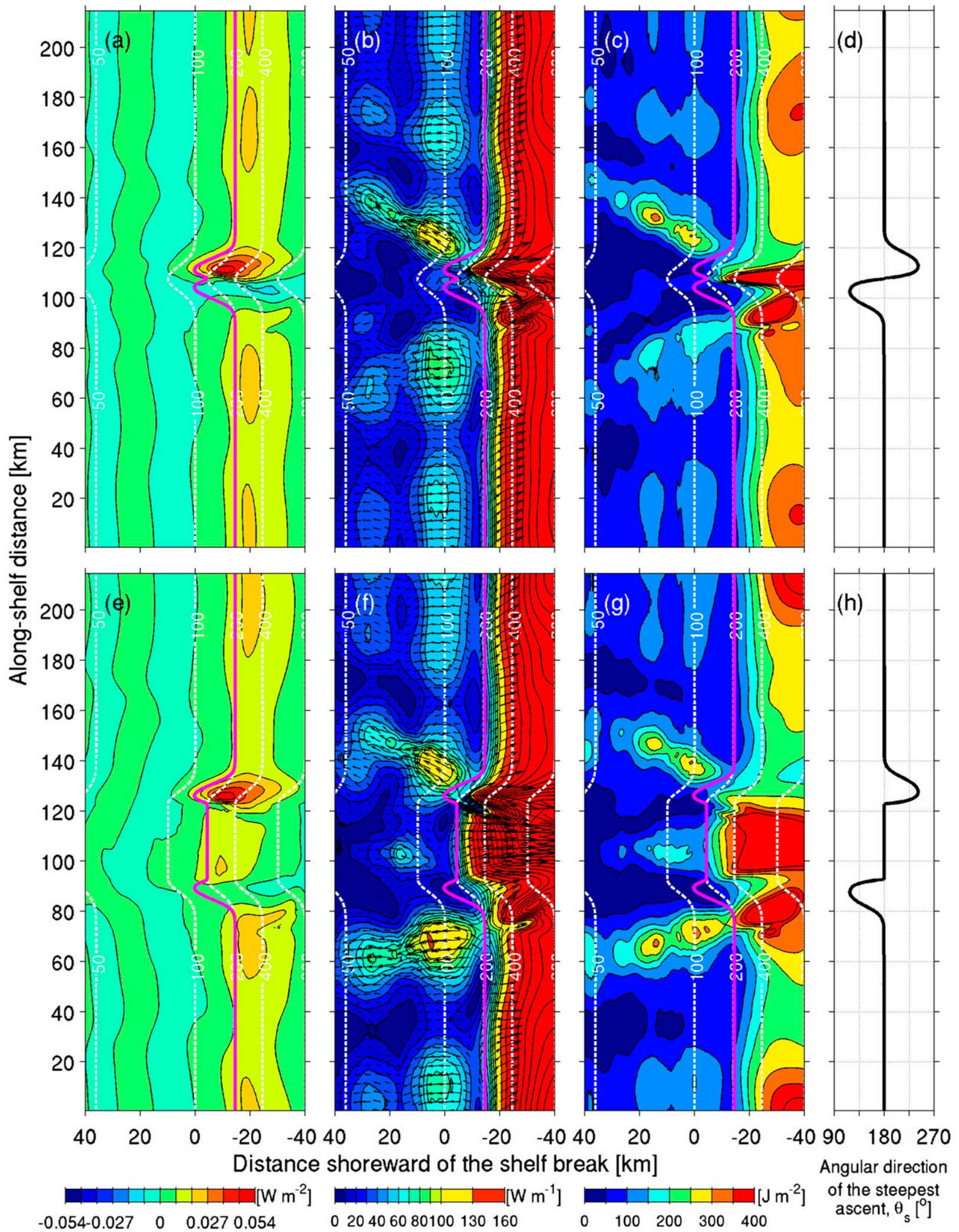

FIG. 4. As in Fig. 3, but for results from ROMS (a)-(d) Run 2 and (e)-(h) Run 3. Simulation parameters are given in Table 1. 
where $G_{n}$ is the Green's function for mode $n$, and $\hat{A}_{s n}$ and $\phi_{s n}$ are the amplitude and phase of the modal source functions, respectively.

Again exploiting $k_{n}$ being spatially uniform on a flat shelf with uniform stratification, the Green's function for a point source is $H_{0}^{(1)}$, the Hankel function of the first kind of zero order (Ahluwalia and Keller 1977). Considering only mode 1 , which is typically dominant in the field (Duda and Rainville 2008; Sherwin 1988) but contains roughly $70 \%$ of the variance on the shelf in the numerical result, the solution becomes

$$
w(x, y, z, t)=\iint_{s} H_{0}^{(1)}\left(k_{1} r_{s}^{\prime}\right) \hat{A}_{s 1}\left(x_{s}, y_{s}\right) \psi_{1}(z) e^{-i\left[\omega t+\phi_{s 1}\left(x_{s}, y_{s}\right)\right]} d x_{s} d y_{s},
$$

where $r_{s}^{\prime}=\left[\left(x-x_{s}\right)^{2}+\left(y-y_{s}\right)^{2}\right]^{1 / 2}$ prescribes the distance from each source point. This expression holds for $w$ from any mode, with substitution required for subscript 1 . The integration over the source area can be performed using discretization and summation to form an approximate solution at any point.

All that is needed to form the mode- 1 solution on the shelf are $\psi_{1}, \hat{A}_{s 1}, \phi_{s 1}$, and $k_{1}$. Because $\psi_{1}(z)$ is independent of $x$ and $y$ on the assumed flat shelf, it is not needed for computing the radiation pattern in the $(x, y)$ plane. We choose the shelfbreak depth, $100 \mathrm{~m}$, as the assumed uniform depth and the vertical wavenumber of the first normal mode to be $m_{1}=\pi / 100 \mathrm{~m}^{-1}$. Substituting $m_{1}$ and the mean buoyancy frequency in the top $100 \mathrm{~m}, N_{0}=0.016 \mathrm{~s}^{-1}$, into the IW dispersion relation provides $k_{1} \approx 2 \pi / 30 \mathrm{~km}^{-1}$.

Despite their cross-slope distributed-source nature, locally generated internal tides in a supercritical-slope scenario (no canyon) in a numerical model have a form that can be back propagated to an apparent source near the site of critical slope (Zhang and Duda 2013). For this reason, the source region in the integral (with $\hat{A}_{s 1} \neq 0$ ) is chosen to be the line (locus) $s(x, y)$ where the slope is critical for the $\mathrm{M}_{2}$ internal tide (Figs. 2 and 3, magenta line; water depth between 130 and $200 \mathrm{~m}$ ). Source point density is $2 \mathrm{~km}^{-1}$ in $y$ along this locus, which is confirmed to be adequate by convergence testing.

The relative phases $\phi_{s 1}$ at the source points are key to the radiation pattern. The four parameters governing phase are the $x$ and $y$ barotropic tidal currents and the $x$ and $y$ bathymetric gradients along the source locus. The barotropic tidal ellipses and phases are essentially uniform on the curve (Fig. 2a), whereas the bathymetric gradient components are variable, with the direction of steepest ascent $\theta_{s}=\tan ^{-1}[(d H / d x) /(d H / d y)]$ varying substantially (Figs. 3a,d). At each source point, the maximum upward velocity occurs at the alignment of the horizontal barotropic velocity vector $\mathbf{U}_{h}(x, y, t)$ and $\theta_{s}$, which is governed almost completely by the structure of $\theta_{s}$. Therefore, $\phi_{s 1} \approx \theta_{s}$ in the baseline calculation (Table 2). Because $\mathbf{U}_{h}$ rotates clockwise, the phase on the southern side of the canyon leads that on the northern side. The line source in the canyon can be conceptually divided into four pieces, each with monotonic spatialphase trend, covering these along- $y$ segments: $\mathrm{C}-\mathrm{B}, \mathrm{C}-\mathrm{D}$, D-E, and F-E (Fig. 3d).

In addition to these important phase variations, results from the numerical model indicate that the conversion rate $C_{v}$ varies across the canyon (Fig. 3a; see sections $3 \mathrm{a}, 4 \mathrm{a}$, and $4 \mathrm{~b}$ for discussions on this), reflecting IW source strength variation. Disregarding this variation by setting $\hat{A}_{s 1}$ constant in the semianalytical model is equivalent to a single-scatter internal-tide solution (the Born approximation; Harrison and Plutchok 1965). A first-order multiple-scattering solution, sometimes called the distorted wave Born approximation (Schiff 1968), could be implemented here using a more complicated semianalytical model incorporating 2D currents, such as used in Griffiths and Grimshaw (2007), providing corrections to the IW-generating currents and a means to approximate $C_{v}$ and $\hat{A}_{s 1}$. However, this would needlessly complicate the simple model without providing much additional insight and would still not be able to duplicate the numerical results. Instead, the multiple-scattering influences on source strength are incorporated in the baseline calculation by applying ROMSderived variations to $\hat{A}_{s 1}$. The justification for this imitation of a multiple-scattering effect is discussed later. For simplicity, variable $\hat{A}_{s 1}$ is restricted to be uniform in each of the source segments A-B, B-D, D-F, and F-G shown in Fig. 3d, with ratios of $\hat{A}_{s 1}$ between the segments being proportional to ratios of the square root of the upslopeaveraged ROMS-computed $C_{v}$ (Run 1 ; section 2b).

A total of 11 calculations with the semianalytical model are reported here (Table 2), including the baseline calculation (Calculation 1). In Calculation 2, $\hat{A}_{s 1}$ is replaced with a uniform function over the entire line source (A-G) to examine the influence of cross-canyon source amplitude variation. In Calculation 3, both $\hat{A}_{s 1}$ and $\phi_{s 1}$ are uniform over the entire line source. The comparison between Calculations 2 and 3 reveals the influence of cross-canyon source phase variation. 

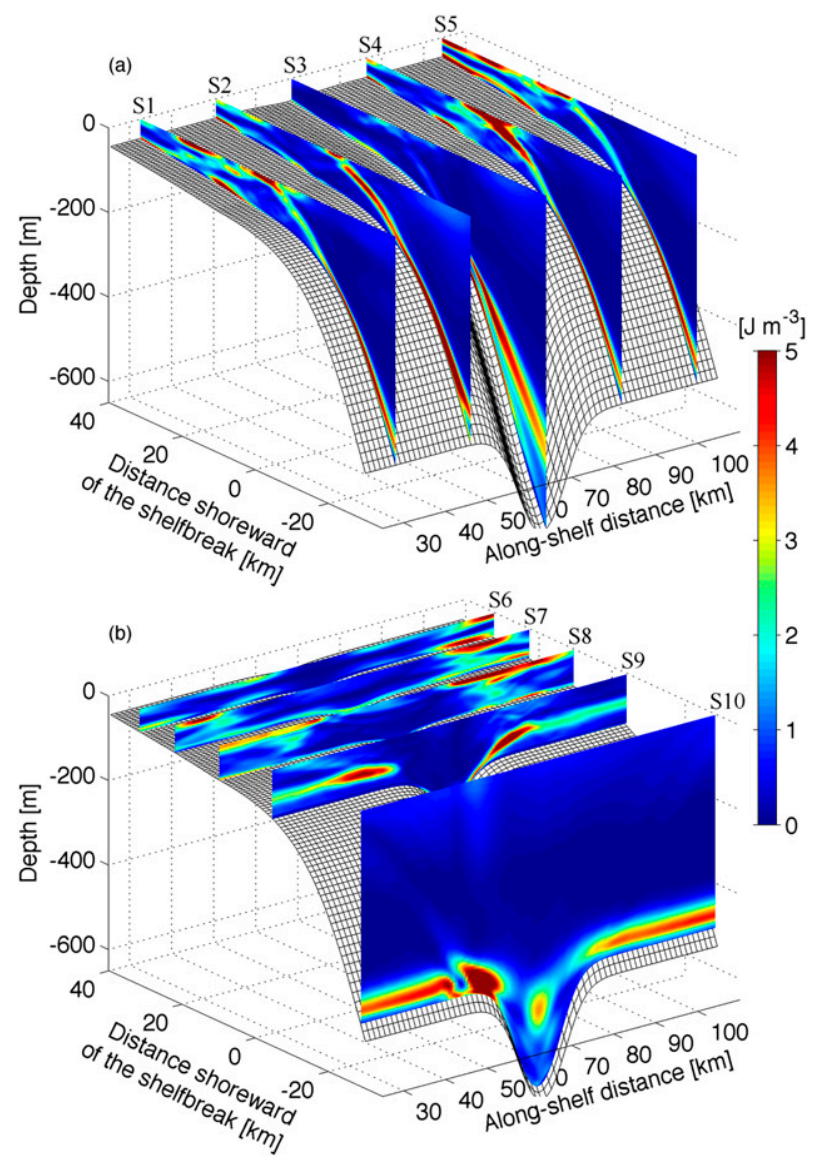

FIG. 5. (a) Cross- and (b) along-shelf sections of the internal wave kinetic energy density from the ROMS control simulation. S1-S10 are the names of the slices.

Calculations 4-11, partial solutions with line source segments, are designed to examine the contribution of each source segment. Note that because the semianalytical model is based on linear wave dynamics, the segment solutions sum to the total solution. However, wave energy does not sum in this way, and this must be kept in mind when examining partial solution, wave energy beam pattern plots. Because of the dramatic change of water depth in the slope sea, solutions of these flat bottom approximation calculations are expected to be invalid offshore of the source locus and are not shown in the figures.

\section{b. Semianalytical results}

The baseline calculation of the semianalytical model (Fig. 6a,b) produces an energy pattern on the shelf qualitatively resembling the asymmetrical beam pattern of the ROMS-simulated kinetic energy (Fig. 3b). In particular, the general orientations, starting positions, and relative strength of the beams are similar for the two results. The phase propagation of the waves is onshore and approximately aligned with the beam axes, as expected. However, discrepancies exist between the numerical and semianalytical solutions. For instance, the beams in the former are patchier, and substantially weaker, $30 \mathrm{~km}$ onshore of the $100-\mathrm{m}$ isobath, and they are more coherent and stay so for a much longer distance in the latter. The discrepancies are consistent with the idealizations of the semianalytical model, including the flat bottom, the single mode, and no viscosity.

When uniform source amplitude and variable source phases are used (Calculation 2; Fig. 6c), the relative beam strength on different sides of the canyon become opposite to the simulated: the southern beam becomes stronger than the northern one. However, other features of the beams remain, including the asymmetrical starting positions (relative to the critical locus). When both source amplitude and phase are set to be uniform along the source locus (Calculation 3; Fig. 6d), the beams become symmetrical with respect to the canyon axis, and the near-canyon ends of the beams become very weak. These results indicate the following:

(i) The bent source locus around the canyon forms the basis of the energy beams through wave interference.

(ii) The cross-canyon source phase variation causes the near-canyon parts of the beams to strengthen and to move southwestward (southeastward) for the

TABLE 2. The list of semianalytic calculations.

\begin{tabular}{clccc}
\hline \hline Calculation index & \multicolumn{1}{c}{ Description } & Source locations & Source amplitude $\hat{A}_{s 1}$ & Source phase $\phi_{s 1}$ \\
\hline 1 & Baseline calculation & A-G & Piecewise uniform & $\theta_{s}$ \\
2 & Uniform source amplitude & A-G & Uniform & Uniform \\
3 & Uniform source amplitude and phase & A-G & Uniform & $\theta_{s}$ \\
4 & Northern canyon flank part & E-F & Uniform & $\theta_{s}$ \\
5 & Northern canyon flank & D-F & Uniform & $\theta_{s}$ \\
6 & North of canyon & F-G & Uniform & $\theta_{s}$ \\
7 & Northern half & D-G & Uniform & $\theta_{s}$ \\
8 & Southern canyon flank part & B-C & Uniform & $\theta_{s}$ \\
9 & Southern canyon flank & B-D & Uniform & $\theta_{s}$ \\
10 & South of canyon & A-B & Uniform & Uniform \\
11 & Southern half & A-D & Un &
\end{tabular}




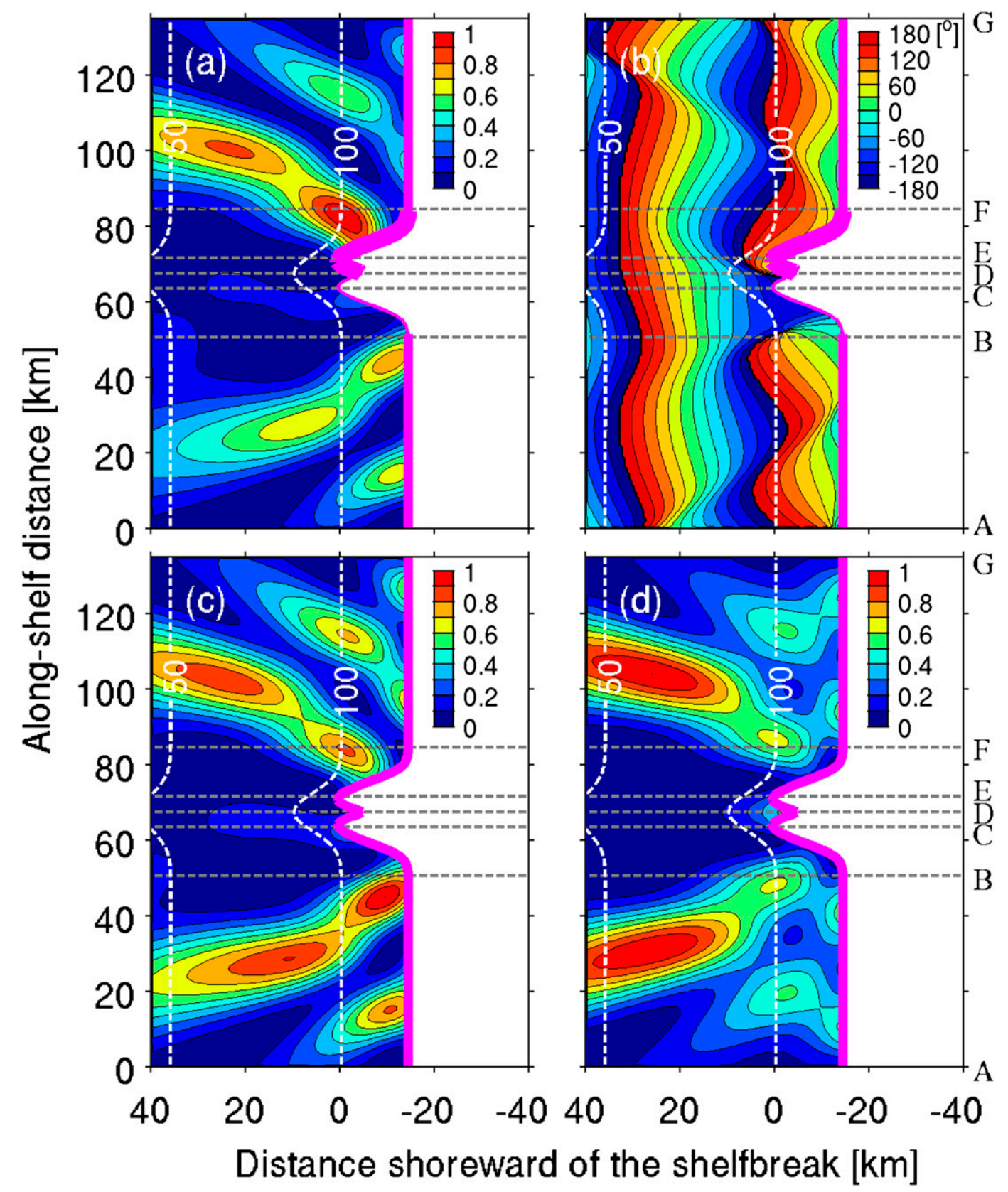

FIG. 6. (a) Energy (wave amplitude squared) and (b) phases of the wave field from the semianalytical baseline calculation with variable source amplitude and phases (Table 2). (c),(d) Energy results for Run 2 (mode-1 sources with uniform amplitude and variable phases) (c) and Run 3 (mode-1 sources with uniform amplitude and phases) (d). Only values "onshore" of the mode- 1 wave sources that are distributed along the critical locus (the magenta line) are shown. The wave energies in (a),(c), and (d) are individually normalized to have unity max. The gray dashed lines separate the line sources (the magenta lines) into segments (see Fig. 3). The thickness of the magenta line portion in each segment is proportional to the wave-source amplitude. Note that the bottom is assumed flat (100 $\mathrm{m}$ deep) in the semianalytical propagation model in all cases, and the isobath contours from the ROMS control run (white dashed lines) are plotted merely for reference.

beam north (south) of the canyon, creating asymmetrical beam starting positions.

(iii) Cross-canyon variation of the source amplitude, as indicated by the cross-canyon variation of $C_{v}$, controls the relative strength of the beams, illustrated by the stronger beam north of the canyon in both ROMS Run 1 and semianalytical Calculation 1. 

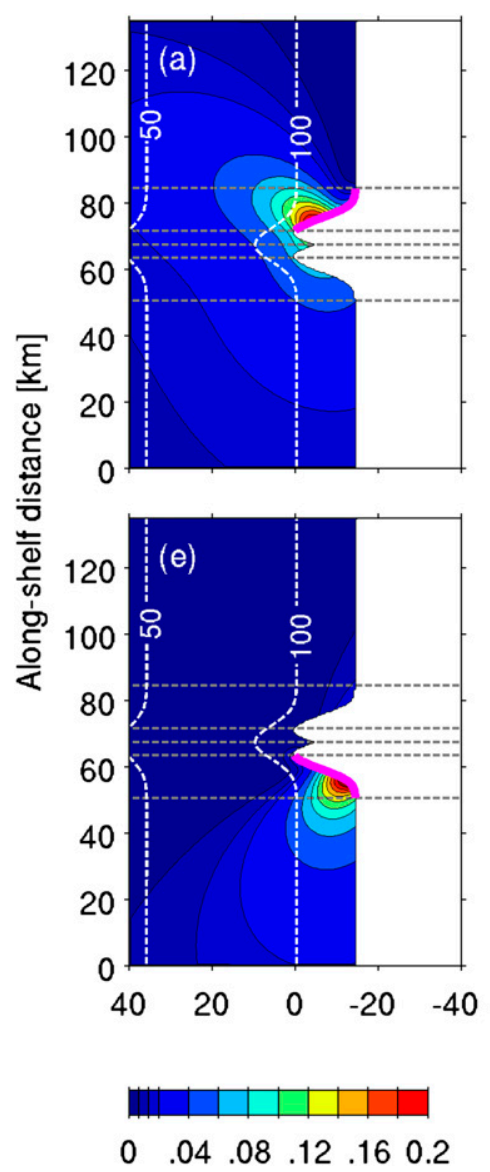
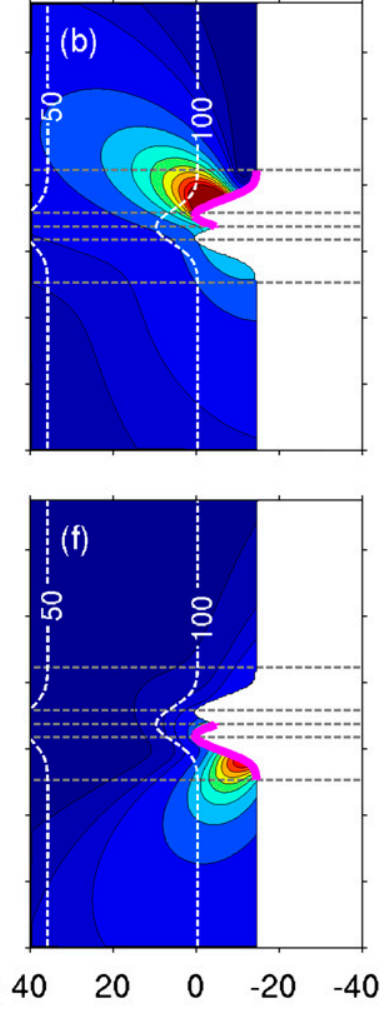
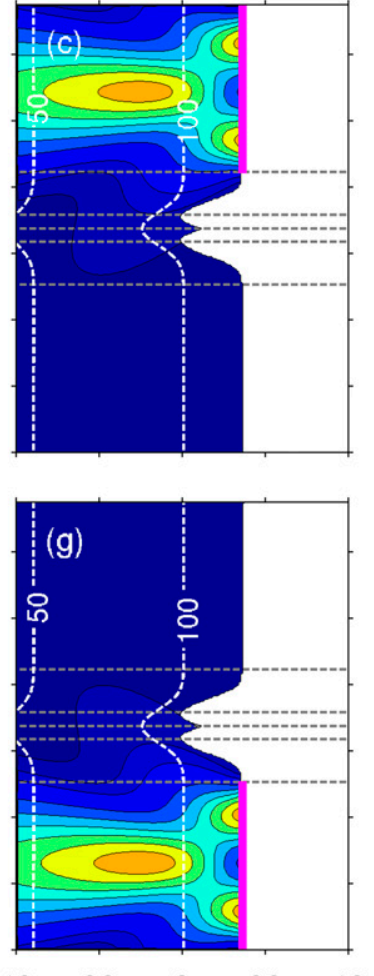

$\begin{array}{lllll}20 & 0 & -20 & -40 & 40\end{array}$

Distance shoreward of the shelfbreak $[\mathrm{km}]$
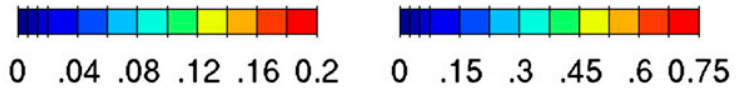
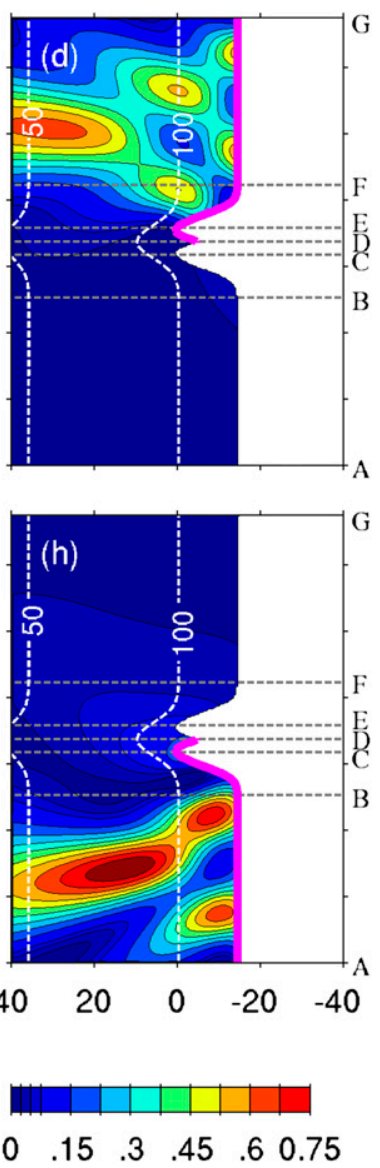

FIG. 7. Wave energy (wave amplitude squared) "onshore" of the critical locus line from semianalytical calculations 4-11 (Table 2) is shown. Each calculation has a uniform-amplitude, variable-phase, mode-1 critical locus wave-source region that spans only part of the domain, with the magenta lines showing the source locations in each panel. The gray dashed lines separate the critical locus into named segments, with names derived from the letters at the right (see Fig. 3). The energy is normalized by the max energy of the wave field for uniform-amplitude, variable-phase wave sources distributed along the entire critical locus from A to G (Calculation 2; Table 2).

The second point is further proven by Run 5 (Table 1) with anticlockwise tidal rotation (opposite to the control simulation; not shown) that produces vertically integrated $\mathbf{F}_{v}$ and $E_{v}$ exactly the same as the north-southflipped Figs. $3 \mathrm{~b}$ and $3 \mathrm{c}$, respectively. The corresponding semianalytical calculations with the source phase on the northern side of the canyon leading that on the southern side also produce amplitude and phase north-south flipped from those in Fig. 6.

Calculations 4-11 of the semianalytical model, with variable-phase segment sources of uniform amplitude (Fig. 7), reveal how each part of the total line contributes to the baseline beam radiation pattern. Calculation 4 (Fig. 7a) shows that the phase increase from $\mathrm{F}$ to $\mathrm{E}$ moves the peak wave energy from the center of the segment (obtained with no phase difference between $\mathrm{F}$ and E; not shown) to the lagging phase (E) end and generates a wide energy beam with the axis pointing northwestward. These essentially reflect the behavior of a phased array. Adding the segment sources D-E into the calculation (Calculation 5; Fig. 7b) reinforces the northwest-pointing beam, and the segments F-E and D-E together generate the near-canyon end of the northern beam. On the southern canyon flank, the phase trend in the segment C-B moves the peak wave energy to the lagging phase (B) end (Fig. 7e) and generates a wide southwest-directed beam. Adding the segment C-D into the calculation (Fig. 7f) has little effect on this beam pattern. Through wave interference, the straight parts of the line sources with no phase difference (Calculations 6 and 10; Figs. 7c,g) generate beamlike, elongated wave peaks pointing westward at the center of the segments onshore of the $100-\mathrm{m}$ isobath. The elongated wave peak north of the canyon generated by the source segment $\mathrm{F}-\mathrm{G}$ (Fig. 7c) and the northwestward beam generated by the source segment D-F (Fig. 7b) together form the 
radiating beam north of the canyon (Fig. 7d). Similarly, the elongated wave peak south of the canyon (Fig. $7 \mathrm{~g}$ ) and the southwestward beam generated by the source segment B-D (Fig. 7f) form the radiating beam south of the canyon (Fig. 7h). Overall, the trending-phase arrays (source segments) on the canyon flanks (D-F and C-B) contribute the most to the near-canyon parts of the beams, and the straight-line uniform-phase sources outside of the canyon contribute the most to the onshore end of the beams.

\section{Discussion}

\section{a. Asymmetrical $C_{v}$ in the canyon: Phase trends in the source region}

In the numerical model, $C_{v}$ is much higher on the northern canyon slope than on the southern one (Fig. $3 a)$. This cross-canyon asymmetry is presumably the result of a feedback effect of the locally generated IWs on the overall barotropic-to-baroclinic conversion, in other words, a multiple-scattering effect. The possibility of this occurring is demonstrated in the work of Kelly and Nash (2010), showing that velocities of incident IWs can strongly affect baroclinic tidal conversion at a slope. The IW generation processes at any canyon slope site can be potentially influenced by incident IWs generated at either (i) the opposite side of the canyon, (ii) a nearby slope on the same side of the canyon, or (iii) a region outside of the canyon. These potential sources of influence are discussed below.

First, to examine the influence of IWs generated on one side of the canyon on conversion at the opposite side, we conducted two numerical simulations with sloped regions inserted into the center of the canyon to widen it in the along-shelf direction by $30 \mathrm{~km}$ (Run 3; Figs. 4e-g) and $60 \mathrm{~km}$ (Run 4; not shown). These along-shelf expansions separate the canyon slopes and presumably reduce the interactions of IWs generated at the opposite sides of the canyon via cylindrical spreading loss. Figure $4 \mathrm{e}$ shows that the $30-\mathrm{km}$ separation slightly increases $C_{v}$ on the southern canyon slope, but has almost no effect on the stronger northern canyon $C_{v}$. A similar pattern is obtained with the $60-\mathrm{km}$ along-shelf expansion at the canyon axis. These indicate that the northern canyon conversion enhancement does not result from IWs generated on the southern canyon slope, although the relatively weak energy conversion on the southern canyon slope is at least partially caused by IWs generated at the northern canyon slope. Notice that the small Run 3 increase of $C_{v}$ on the southern canyon slope and the slope immediately south of the canyon is able to substantially enhance the onshore baroclinic energy flux and IW kinetic energy in the beam south of the canyon (Figs. 4f,g). This provides additional evidence that the along-shelf distribution of $C_{v}$ controls the relative strength of the beams.

Second, analysis of the trend of source phase $\phi_{s 1}$ as a function of $s(x, y)$ on the northern canyon slope shows that it is favorable for enhancing energy conversion on the same slope. The phase of a wave moving along $s$ has spatial dependence $\Delta \phi \approx k \Delta m$, where $\Delta m$ is distance along $s$ and where the approximate equality arises because $s$ may not be straight and because the phase structure of the complex Hankel function solution in the near field deviates slightly from $k \Delta m$. When $\Delta \phi_{s 1}=\Delta \phi$, the generating force from the barotropic wave is aligned in phase with waves generated along the line, allowing resonant generation and what may be considered multiple scattering in the barotropic-to-baroclinic tide conversion process.

To examine this in detail, for mode- 1 IWs the mean phase increase rate along $s$ in the central part of the segment $\mathrm{F}-\mathrm{E}, d \phi_{s 1} / d m\left(\approx d \theta_{s} / d m\right.$; see section $\left.3 \mathrm{a}\right)$, is about $1 / 10 \mathrm{rad} \mathrm{km}^{-1}$ (Fig. 3), slightly less than the horizontal wavenumber at 200-m depth, $k_{1}=2 \pi / 50 \mathrm{rad} \mathrm{km}^{-1}$. Because $d \phi_{s 1} / d m$ is close to $k_{1}$, the resonance can occur. For example, near the lagging phase end (E) of the (phased array) segment F-E, the locally generated waves and the waves generated along the segment have similar total phases, $k_{1} \Delta m-\omega_{\mathrm{M}_{2}} t+\phi_{s 1}(\mathrm{~F})$. That is, the pressure perturbations of the waves arriving from along the segment are positively correlated with $W$ generated by the local barotropic flow, so that enhancement of $C_{v}$ near $\mathrm{E}$ is enabled. This is similar to the enhanced conversion scenario examined by Kelly and Nash (2010). Moreover, because $k_{1}$ decreases with increasing water depth, $d \phi_{s 1} / d m$ is closer to $k_{1}$ in the northern canyon slope region slightly offshore of the 200-m isobath. Therefore, we expect more northern canyon slope enhancement of $C_{v}$ toward the $\mathrm{E}$ end slightly offshore of the 200-m isobath. These are all consistent with the pattern of $C_{v}$ in the numerical model (Fig. 3a) and provide an explanation for the $C_{v}$ enhancement on the northern canyon slope in ROMS based on the structure of $\phi_{s 1}$. Finally, because the resonance effect accumulates along the northern canyon slope toward the lagging phase sources at the shallow end, we expect the $C_{v}$ to be more enhanced in longer canyons (larger $L_{c}$ ). This is also consistent with simulations of different canyon length (see the end of the next section).

This effect should also occur on the southern canyon slope, enhancing $C_{v}$ toward the lagging phase (B) end of that segment. The numerical results show slightly elevated $C_{v}$ on the slope immediately south of the canyon (outside of the canyon perimeter), more clearly seen in 
the example with the two canyon slopes separated by $30 \mathrm{~km}$ (Fig. 4e). The causes for the south canyon $C_{v}$ enhancement being weaker than the north canyon enhancement remain unclear. One possible reason is that IWs generated in the canyon axis region (between lines $\mathrm{C}$ and $\mathrm{E})$ may reinforce the $C_{v}$ enhancement on the northern canyon slope as the phase increases from $\mathrm{C}$ toward $\mathrm{E}$, while there is no equivalent reinforcement for the $C_{v}$ enhancement on the southern canyon slope.

The described mechanism of source phase variation allowing a resonant generation effect to occur is also consistent with the fact that the cross-canyon asymmetrical distribution of $C_{v}$ is controlled by the sense of the barotropic tidal rotation. Run 5 with anticlockwise tidal rotation produces $C_{v}$ distribution exactly northsouth flipped from that in the control run (not shown).

Finally, it is unclear how the IWs generated on the slope outside of the canyon affect the IW generation processes within the canyon. However, $C_{v}$ on the slope outside of the canyon has moderate variation in the along-shelf direction (Fig. 3a), and the variation becomes more periodic with a wavelength of about $50 \mathrm{~km}$ when the along-shelf coverage of the model is expanded (Fig. 4a). The 50-km wavelength is consistent with the mode-1 IW wavelength at 200-m water depth. Because the canyon is the only possible source of irregularity in the along-shelf direction, the along-shelf variation of $C_{v}$ on the slope outside of the canyon in the numerical model must be related to IWs generated within the canyon. Notice that the slightly elevated $C_{v}$ on the slope outside of the canyon enhances the onshore baroclinic energy flux to their west (Figs. $3 b$ and $4 b, f$ ).

\section{b. Supplementary numerical simulations}

To further study the mechanism of baroclinic waves enhancing $C_{v}$ on the northern canyon slope and to examine the effect of canyon geometry on the crosscanyon $C_{v}$ distribution, a series of numerical simulations with different values of $W_{c}$ and $L_{c}$ were conducted (Runs 6-13 in Table 1). Figures 8 and 9 show example results from the simulations. The values of $W_{c}$ and $L_{c}$ are guided by the parameter ranges of MAB shelfbreak canyons: $2.5<W_{c}<10 \mathrm{~km}$ and $5<L_{c}<20 \mathrm{~km}$. The deeper slopes in all these topographies, including at the canyon sides, are supercritical to $\mathrm{M}_{2}$ IWs, and tidal rotations are all clockwise. The adjustments also alter the detailed shape of the critical locus and the phase trend $d \theta_{s} / d m\left(\approx d \phi_{s 1} / d m\right)$.

Although the basic pattern of asymmetrical $C_{v}$ distribution across the canyon persists, the strength of the asymmetry, which can be represented by the maximum $C_{v}$ on the northern canyon slope varies with canyon geometry (Figs. 8,9 ). In particular, the maximum $C_{v}$ increases with increasing $L_{c}$ and with decreasing $W_{c}$, in concert with variations of mean $d \theta_{s} / d m$. In other words, the maximum $C_{v}$ on the northern canyon slope and $d \theta_{s} / d m$ are positively correlated (Fig. 10a). This is consistent with the multiple-scattering resonance effect because, as $d \theta_{s} / d m$ increases toward $k_{1}$, the resonance effect becomes stronger and enhances $C_{v}$ on the northern canyon toward a peak value. Ideally, the $C_{v}$ enhancement would weaken once $d \theta_{s} / d m$ becomes greater than $k_{1}$. Although the simulated trend for $d \theta_{s} / d m>k_{1}$ given by the single simulation of $W_{c}=2.5 \mathrm{~km}$ (the farthest triangle to the right of Fig. 10a) does not agree with this interpretation, it does indicate a somewhat reduced rate of $C_{v}$ enhancement with increasing $d \theta_{s} / d m$. A number of factors could contribute to this discrepancy, including the critical locus being bent and the variation of $k_{1}$ due to the varying critical locus depth.

The simulations provide other evidence for the multiplescattering resonance effect. The evidence is given by the steeper trend between the maxima in $C_{v}$ and altered $L_{c}$-induced phase variation rate, when compared with the trend between the maxima in $C_{v}$ and altered $W_{c}$-induced phase variation rate (Fig. 10a), and by the consistency of the two trends when the maxima in $C_{v}$ are replotted against the product of the $d \theta_{s} / d m$ and $\left(L_{c} / L_{c 0}\right)^{1 / 2}$ (Fig. 10b). This weighting of the phase rate by the canyon length scale $L_{c}$ accounts for the increased accumulation of resonant waves that would be expected in longer canyons, mentioned in section $4 \mathrm{a}$. Note that the square root dependence (rather than linear) of the $L_{c}$ normalization in Fig. 10b is empirical and the exact dynamical reason for this is unclear.

\section{c. Applicability of the findings}

A remaining question is how applicable our findings about the asymmetrical internal-tide generation in the shelfbreak canyon and the beam pattern of onshore baroclinic energy radiation are to canyons of different geometry and bottom slope. Runs 6-13 (see Figs. 8 and 9, for examples) show that the general patterns of asymmetrical internal-tide generation and onshore beam radiation persist within the tested ranges of $W_{c}$ and $L_{c}$ that represent the variability of the MAB canyon geometry. However, the extent of the generation asymmetry and details of the radiation beams, for example, the relative strength of the beams, vary with the canyon geometry. For instance, when the canyon width increases to $20 \mathrm{~km}$ (Run 6; Figs. 8a-d), the $C_{v}$ enhancement on the northern canyon slope is reduced, and the radiation beam south of the canyon becomes slightly stronger than the one north of the canyon, opposite to the relative beam strength in the control run (Fig. 3). It is possible that the mechanisms described in this paper work only for parameters 

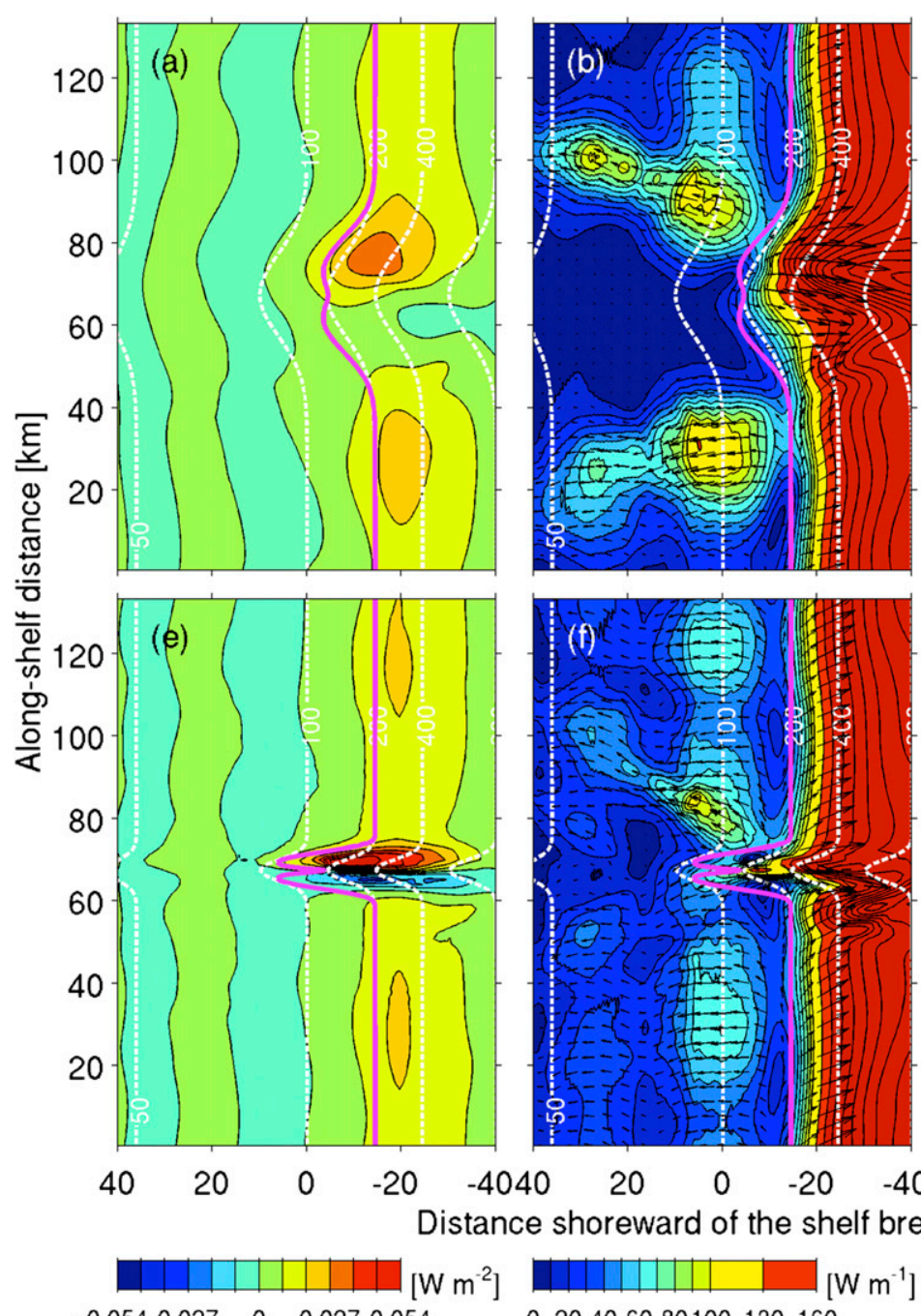

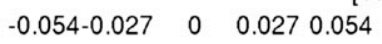

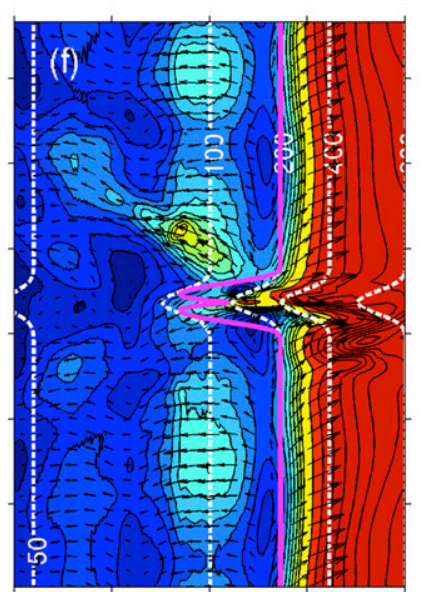

20
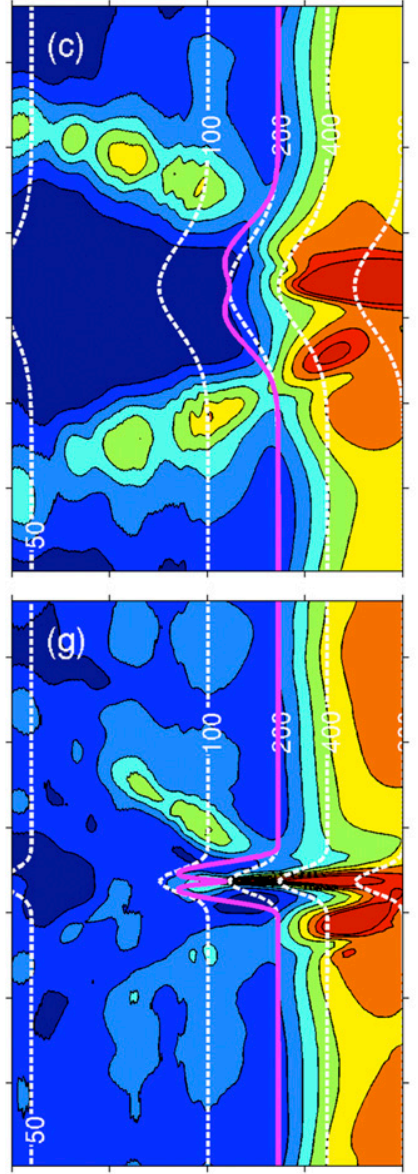

0

\begin{abstract}
$\begin{array}{llll}0 & -20 & -4040 & 20\end{array}$
\end{abstract}
reak $[\mathrm{km}]$
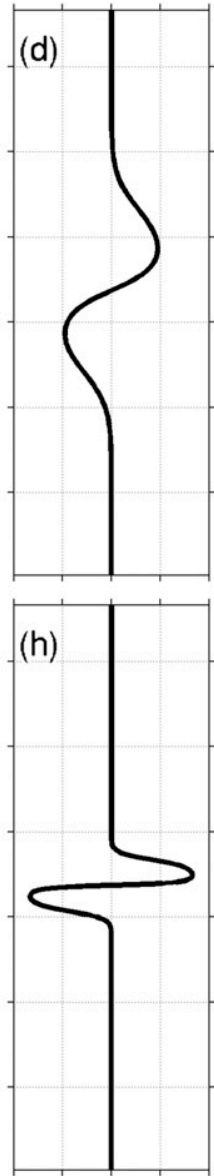

$180 \quad 270$

Angular direction of the steepest ascent, $\theta_{\mathrm{s}}\left[{ }^{\circ}\right]$

FIG. 8. As in Fig. 3, but for results from ROMS (a)-(d) Run 6 and (e)-(h) Run 9 (see Table 1).

in certain ranges. For instance, the internal tides might not be sensitive to the topographic variation when the canyon becomes very narrow with respect to IW horizontal wavelengths, or single-scatter phased source array radiation normal to the array may diminish when the canyon becomes too long. These might result in patterns of internal-tide generation and propagation different from what has been described here. A full description of the parameter limits over which the described findings become invalid is beyond the scope of this work and left for future studies.

Here, the deeper slopes in all tested bathymetries are supercritical to IWs at the forcing frequency, and the semianalytical model is based on the (consistent) assumption that the wave sources can be distributed along a critical locus line. It is likely that when the canyon side slopes become subcritical, the distribution of internal-tide generation will be less confined around the critical locus, and the internal-tide generation and onshore energy radiation patterns described in this study will change.

The internal-tide generation in real shelfbreak canyons is likely to be more complicated due to geometric irregularity, incident internal tides, or variation of ocean conditions. For instance, the axis of the Hudson Canyon has two $60^{\circ}$ bends, IWs from the deep sea have been observed in that canyon (Hotchkiss and Wunsch 1982), and cross-shelf movement of the Mid-Atlantic Bight shelfbreak front can alter the stratification in the canyons. All of these factors could modify the patterns of internal-tide generation and radiation from their appearance here, as suggested by the work of Kelly and Nash (2010) and also studies of the Monterey Canyon showing strong influences of stratification on the IW 


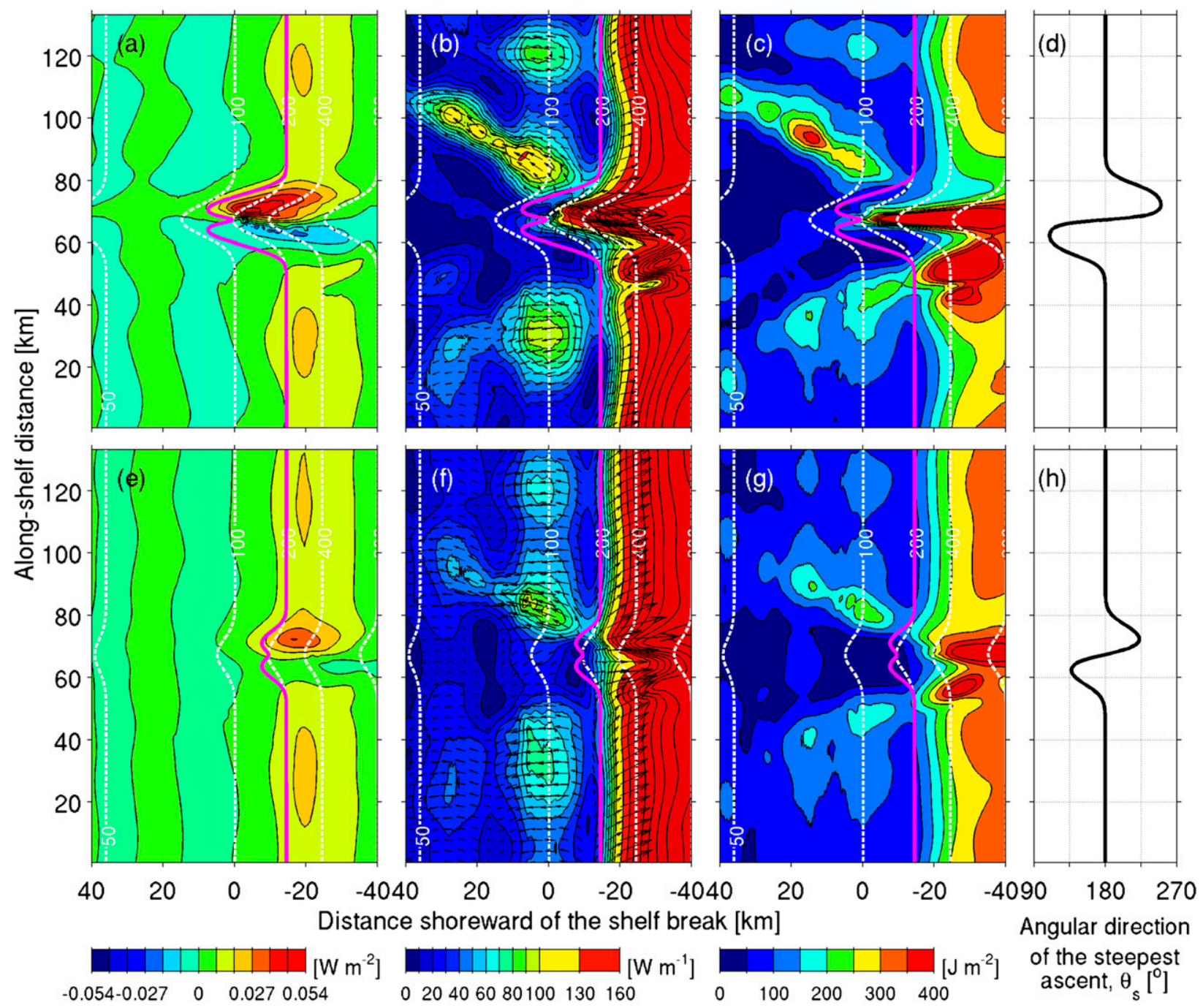

FIG. 9. As in Fig. 3, but for results from ROMS (a)-(d) Run 11 and (e)-(h) Run 13 (see Table 1).

fields (e.g., Hall et al. 2014; Zhao et al. 2012). Therefore, case-by-case studies are likely needed to understand internal tides at specific shelfbreak canyons or internaltide variability under changing conditions.

\section{Summary}

Numerical simulations with barotropic $\mathrm{M}_{2}$ tidal forcing and idealized canyon topography that is supercritical in slope for $\mathrm{M}_{2}$ IWs confirm the Petruncio et al. (2002) findings that the internal tides generated in a symmetrical canyon are stronger on one side of the canyon. For clockwise (anticyclonic) tidal rotation, the vertically integrated barotropic-to-baroclinic energy conversation rate $C_{v}$ is much higher on the northern canyon slope (the upstream side in terms of the coastal-trapped wave propagation). Sensitivity simulations show that the basic cross-canyon asymmetrical pattern of $C_{v}$ does not change with canyon geometry within the variability range of MAB shelfbreak canyons, but the extent of the $C_{v}$ enhancement on the northern canyon slope varies.

The major results center around two aspects of internaltide forcing. One is that the phase variation in the spatially distributed internal-tide source function can be in resonance with propagating internal tides. To explain further, the $C_{v}$ enhancement on the northern canyon side slope is linked to internal tides that are generated on that same slope, as opposed to those generated elsewhere. The mechanism is that the spatial gradient of the source phases (controlled mostly by the change of the direction of the local steepest bathymetric ascent) along the critical locus on the northern canyon slope matches the spatial-phase gradient of the freely propagating internal tide (i.e., the horizontal wavenumber), so that 


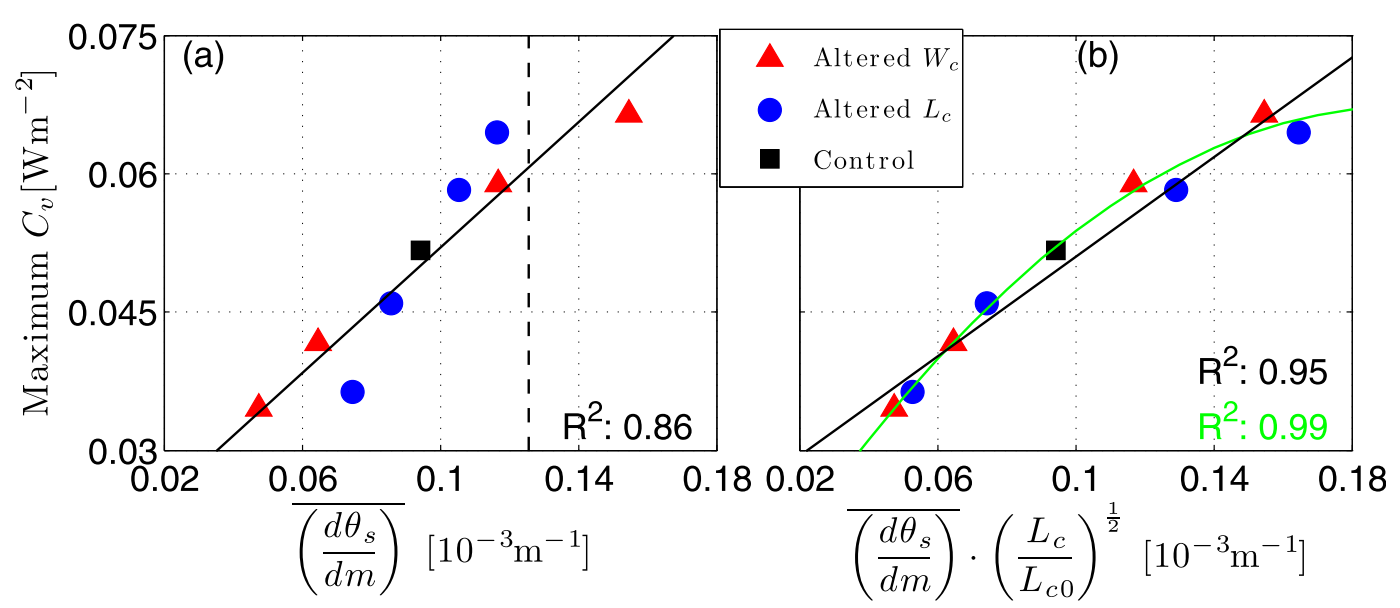

FIG. 10. For nine ROMS simulations (Runs 1 and 6-13), $\max C_{v}$ on the northern canyon slope vs (a) the mean $d \theta_{s} / d m$ along the critical locus on the northern canyon slope and (b) the product of the mean $d \theta_{s} / d m$ and square root of the ratio of canyon length $\left(L_{c}\right)$ to its control value $\left(L_{c 0}=10 \mathrm{~km}\right)$. The symbols represent different simulations, the control one and the ones with altered parameter values. The dashed black line in (a) indicates the horizontal mode- 1 wavenumber $k_{1}$ at 200-m depth. The solid black lines represent empirical linear least squares fits to all the symbols: $y=0.34 x+0.018$ and $y=0.27 x+0.024$ for (a) and (b), respectively; the green line in (b) represents an empirical quadratic least squares fit to all the symbols: $y=-1.52 x^{2}+0.59 x+0.01 ; R^{2}$ values of all the fits are shown.

propagating waves reinforce the generation process and thus enhance $C_{v}$. The mechanism is related to the incident wave effect on slope internal-tide generation (Kelly and Nash 2010). A similar effect occurs on the southern canyon slope, but less effectively, and only generates weak $C_{v}$ enhancement outside of the canyon perimeter. As far as IWs crossing the canyon are concerned, internal tides generated on the northern canyon slope act to diminish the internal-tide generation on the southern slope, while effects in the opposite sense are hardly noticeable.

The other aspect of the internal-tide canyon forcing is that the phase variation in the distributed-source function also controls beam formation on the shelf. In summary, the spatial distribution of the phase of internal-tide forcing results in beams in the case of single scattering (baroclinic waves forced by barotropic waves alone), but the distribution does not explain the relative beam strengths on the two sides of the canyon. However, a sufficient explanation for the shelf internal-tide pattern is obtained using the spatial-phase distribution and a multiple-scattering effect and is substantiated with multiple numerical and semianalytical calculations.

To summarize the numerically simulated wave fields, the depth-integrated IW kinetic energy on the neighboring continental shelf is primarily in beams radiating onshore away from both canyon sides. The beams are asymmetrical in terms of their starting position relative to the canyon flank. The beam north of the canyon starts from the middle of the northern canyon flank, while the beam on the south side starts from the outskirt shelfbreak region south of the canyon. In most of the simulations, the beam on the north side is stronger than the one on the south side. However, the relative strength of the beams is sensitive to the cross-canyon distribution of the barotropic-to-baroclinic energy conversion rate, such that the opposite relative beam strength can be generated when the conversion rate becomes less asymmetrical in a wide canyon.

The canyon topography is the ultimate cause of the described asymmetrical internal-tide generation and onshore beam radiation, as the variation of the direction of the steepest bathymetry ascent within the canyon determines both the amplitude and phase variation of the locally generated internal tides. The source phase variation in the clockwise tidal rotation scenario allows the multiple-scattering effects, producing the $C_{v}$ enhancement on the northern canyon slope and also forms the phased arrays on the canyon flanks generating the near-canyon parts of the radiation beams on the shelf. The rotation sense of the barotropic tidal ellipse plays a role in the internal-tide pattern that will arise for a given canyon bathymetry, so to the degree that Earth's rotation controls the sense of the internal-tide ellipse, Earth's rotation plays a role. Earth's rotation also affects the internal-tide horizontal wavenumber, thus the internal-tide generation and radiation patterns.

Finally, internal-tide generation in real shelfbreak canyons is anticipated to be more complicated than the processes modeled here due to geometric irregularity, incident internal tides, or variation of ocean conditions. Thus, detailed information concerning these factors is 
probably required for understanding internal tides at particular shelfbreak canyons.

Acknowledgments. We thank Drs. Ying-Tsong Lin and James Lynch for useful discussions during the course of the study. All three authors were supported by Office of Naval Research (ONR) Grant N00014-11-1-0701. WGZ was additionally supported by the National Science Foundation (NSF) Grant OCE-1154575, and TFD was additionally supported by NSF Grant OCE-1060430. Comments from two anonymous reviewers and the editor led us to increase the number of calculations presented here and thus improve the paper.

\section{REFERENCES}

Ahluwalia, D. S., and J. B. Keller, 1977: Exact and asymptotic representations of the sound field in a stratified ocean. Wave Propagation and Underwater Acoustics, J. B. Keller and J. S. Papadakis, Eds., Lecture Notes in Physics, Vol. 70, Springer, 14-85.

Allen, S. E., and X. Durrieu de Madron, 2009: A review of the role of submarine canyons in deep-ocean exchange with the shelf. Ocean Sci., 5, 607-620, doi:10.5194/os-5-607-2009.

Apel, J. R., 1987: Principles of Ocean Physics. Academic Press, $634 \mathrm{pp}$.

Carter, G. S., 2010: Barotropic and baroclinic $\mathrm{M}_{2}$ tides in the Monterey Bay region. J. Phys. Oceanogr., 40, 1766-1783.

Chapman, D. C., 1985: Numerical treatment of cross-shelf open boundaries in a barotropic ocean model. J. Phys. Oceanogr., 15, 1060-1075.

Chiou, M.-D., S. Jan, J. Wang, R.-C. Lien, and H. Chien, 2011: Sources of baroclinic tidal energy in the Gaoping Submarine Canyon off southwestern Taiwan. J. Geophys. Res., 116, C12016, doi:10.1029/2011JC007366.

Duda, T. F., and L. Rainville, 2008: Diurnal and semidiurnal internal tide energy flux at a continental slope in the South China Sea. J. Geophys. Res., 113, C03025, doi:10.1029/ 2007JC004418.

_- A. E. Newhall, G. G. Gawarkiewicz, M. J. Caruso, H. C. Graber, Y.-J. Yang, and S. Jan, 2013: Significant internal waves and internal tides measured northeast of Taiwan. J. Mar. Res., 71, 47-82.

Flather, R. A., 1976: A tidal model of the northwest European continental shelf. Mem. Soc. Roy. Sci. Liege, 10, 141-164.

Gregg, M. C., R. A. Hall, G. S. Carter, M. H. Alford, R.-C. Lien, D. P. Winkel, and D. J. Wain, 2011: Flow and mixing in Ascension, a steep, narrow canyon. J. Geophys. Res., 116, C07016, doi:10.1029/2010JC006610.

Griffiths, S. D., and R. H. J. Grimshaw, 2007: Internal tide generation at the continental shelf modeled using a modal decomposition: Two-dimensional results. J. Phys. Oceanogr., 37, $428-451$.

Hall, R. A., M. H. Alford, G. S. Carter, M. C. Gregg, R.-C. Lien, D. J. Wain, and Z. Zhao, 2014: Transition from partly standing to progressive internal tides in Monterey Submarine Canyon. Deep-Sea Res. II, doi:10.1016/j.dsr2.2013.05.039, in press.

Harrison, M., and R. Plutchok, 1965: Scattering theory for onedimensional problems. J. Acoust. Soc. Amer., 37, 84-89.
Hotchkiss, F. S., and C. Wunsch, 1982: Internal waves in Hudson Canyon with possible geological implications. Deep-Sea Res. I, 29, 415-442.

Jachec, S. M., O. B. Fringer, M. G. Gerritsen, and R. L. Steet, 2006: Numerical simulation of internal tides and the resulting energetics within Monterey Bay and the surrounding area. Geophys. Res. Lett., 33, L12605, doi:10.1029/2006GL026314.

Jackson, C. R., 2004: An Atlas of Internal Solitary-like Waves and their Properties. 2nd ed. Global Ocean Associates, 560 pp.

Kelly, S. M., and J. D. Nash, 2010: Internal-tide generation and destruction by shoaling internal tides. Geophys. Res. Lett., 37, L23611, doi:10.1029/2010GL045598.

Kunze, E., L. K. Rosenfeld, G. S. Carter, and M. C. Gregg, 2002: Internal waves in Monterey Submarine Canyon. J. Phys. Oceanogr., 32, 1890-1913.

Lee, I.-H., R.-C. Lien, J. T. Liu, and W.-S. Chuang, 2009: Turbulent mixing and internal tides in Gaoping (Kaoping) Submarine Canyon, Taiwan. J. Mar. Syst., 76, 383-396, doi:10.1016/ j.jmarsys.2007.08.005.

Orlanski, I., 1976: A simple boundary condition for unbounded hyperbolic flows. J. Comput. Phys., 21, 251-269.

Petruncio, E. T., J. D. Paduan, and L. K. Rosenfeld, 2002: Numerical simulations of the internal tide in a submarine canyon. Ocean Modell., 4, 221-248.

Rainville, L., and R. Pinkel, 2006: Propagation of low-mode internal waves through the ocean. J. Phys. Oceanogr., 36, 12201236.

—, T. M. S. Johnston, G. S. Carter, M. A. Merrifield, R. Pinkel, P. F. Worcester, and B. D. Dushaw, 2010: Interference and propagation of the $\mathrm{M}_{2}$ internal tide south of the Hawaiian Ridge. J. Phys. Oceanogr., 40, 311-325.

Schiff, L. I., 1968: Quantum Mechanics. McGraw-Hill Book Company, 544 pp.

Shchepetkin, A. F., and J. C. McWilliams, 2005: The Regional Oceanic Modeling System (ROMS): A split-explicit, freesurface, topography-following-coordinate oceanic model. Ocean Modell., 9, 347-404.

Sherwin, T. J., 1988: Analysis of an internal tide observed on the Malin Shelf, north of Ireland. J. Phys. Oceanogr., 18, 10351050.

Shroyer, E. L., 2012: Turbulent kinetic energy dissipation in Barrow Canyon. J. Phys. Oceanogr., 42, 1012-1021.

Swart, N. C., S. E. Allen, and B. J. W. Greenan, 2011: Resonant amplification of subinertial tides in a submarine canyon. J. Geophys. Res., 116, C09001, doi:10.1029/2011JC006990.

Vlasenko, V., N. Staschuk, and K. Hutter, 2005: Baroclinic Tides: Theoretical Modeling and Observational Evidence. Cambridge University Press, $351 \mathrm{pp}$.

Warner, J. C., C. R. Sherwood, H. G. Arango, R. P. Signell, and B. Butman, 2005: Performance of four turbulence closure models implemented using a generic length scale method. Ocean Modell., 8, 81-113.

Zhang, W. G., and T. F. Duda, 2013: Intrinsic nonlinearity and spectral structure of internal tides at an idealized Mid-Atlantic Bight shelfbreak. J. Phys. Oceanogr., 43, 2641-2660.

_ G. G. Gawarkiewicz, D. J. McGillicuddy, and J. L. Wilkin, 2011: Climatological mean circulation at the New England shelf break. J. Phys. Oceanogr., 41, 1874-1893.

Zhao, Z., M. H. Alford, R.-C. Lien, M. C. Gregg, and G. S. Carter, 2012: Internal tides and mixing in a submarine canyon with time-varying stratification. J. Phys. Oceanogr., 42, 21212142 . 